\title{
Planning of production territories for preservation and improvement of the ecological situation in the cities
}

\author{
Tamara Narezhnaya ${ }^{1, *}$, and Ilya Zvonov ${ }^{1}$ \\ ${ }^{1}$ Moscow State University of Civil Engineering, Yaroslavskoye Shosse, 26, 129337, Moscow, Russia
}

\begin{abstract}
The authors consider a relevant problem of preservation and improvement of the ecological situation in large and medium industrial cities. Recently the cities suffer because of the increasing pollution. While motor transport is being transferred to the electric power, expand application of renewable types of energy, the industrial enterprises present a great danger. Even though the enterprises throw out many substances to the environment, it would be wrong to estimate them only as a negative phenomenon. They work for people and for the economy of the state. Three integrated options, describing the most typical situations, in which there are production objects during functioning and development, are considered in the article. The most often found schemes of planning of the production territories, relating to industries, which are historically placed in the cities, are analysed. The mechanism of distribution of pollution in these territories is considered. The generalized measures for each option of reconstruction transformations are offered.
\end{abstract}

\section{Introduction}

The environmental problem is the problem of the relationship between the nature and human society and as well as the problem of preservation of the environment. Human has always been connected with the world around, but the more the humankind developed, the stronger it influenced the nature. For many years people increased the technical capabilities, especially in the second half of the 20th century. Then because the intensive industrialization and urbanization the negative impact of the person on the nature began to exceed the ability of ecological systems to regeneration. It has led to the violation of natural circulation of substances, thus the future generations and their lives are under the threat. Now more than one million substances are artificially received and most of them are put into the environment. The substances, produced by human are alien for the biosphere and as the result hardly decomposed and not-decomposed substances are getting accumulated.

The problem of environmental pollution of the city gains more and more global character. It concerns practically each person, therefore these research have great importance and relevance. For a long time Serious contradictions between the nature and industrialization

\footnotetext{
* Corresponding author: narejnaya@mail.ru
} 
have been revealed years ago, it is especially obvious in the cities with hundreds of pollution sources. Search of solution is obligatory for preservation of the future life.

\section{Materials and Methods}

The mechanism of pollution of the urban environment is difficult and includes many factors. According to their sources, pollutants of the environment divide into two goups: primary and secondary (Fig. 1).

Primary pollution gets into the environment directly from the sources, but the danger of primary pollution consists in the joint pollution with many substances, which into chemical reactions enter among themselves as a result of which much more toxic substances. As the result there appear a group of secondary pollution are formed [1].

The ecological situation is defined, both by specifics of local climatic conditions, and by character and scales of impact on the environment of the enterprises of the industry, transport, municipal services, etc.

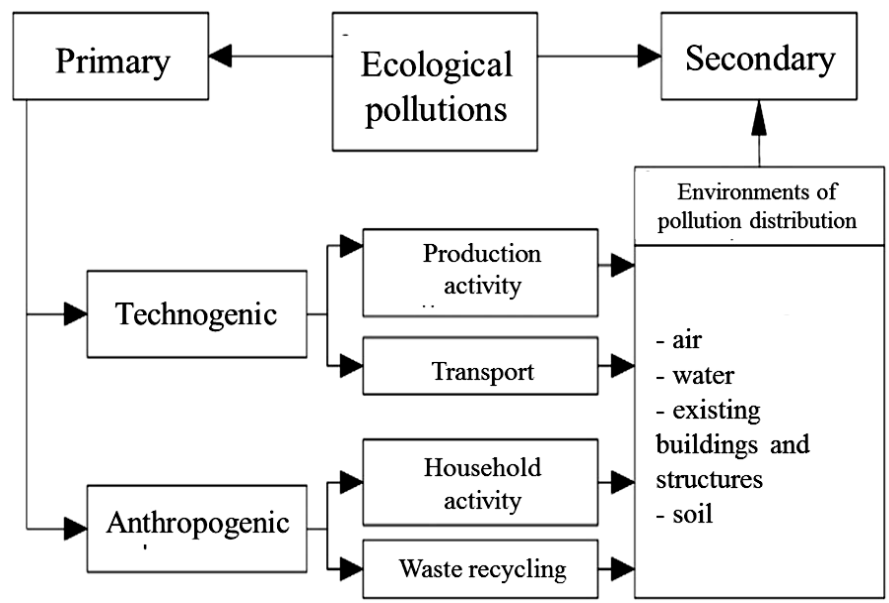

Fig. 1. Structure of ecological pollution in the city.

Primary pollution consist of technogenic and anthropogenic sources (Fig. 1).

Treat anthropogenic sources of pollution:

- household activity;

- recycling.

Technogenic sources of pollution include:

- transport pollution and pollution, formed during the work of different types of transport;

- production, that is emission of the industrial enterprises;

- energy industry.

The long-term analysis proves that the main sources, polluting the environment in industrialized countries, are the motor transport, the enterprises of fuel-and-energy complex, the enterprise of mechanical engineering, the enterprise of heavy and chemical industry, etc. [2]. Distribution of pollution is the following (approximately): motor transport makes about one quarter of the total pollution, and as much it is the share of power. And about a half of total pollution is the share of industry influence. Ratios of volumes of pollution depending on a source are given in fig. 2 . 
$\square$ Heat-and-power engineering

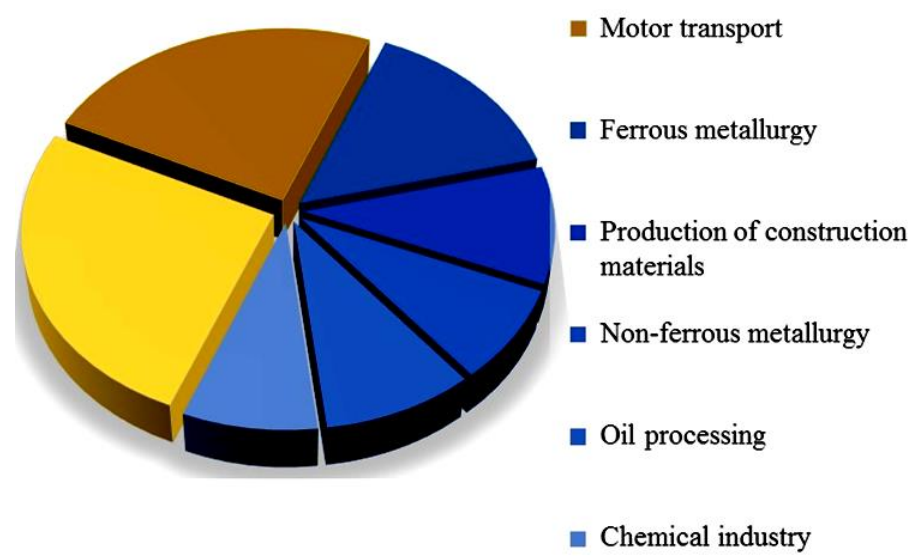

Fig. 2. Specific distribution according to types of pollution sources.

The state of environment in the city depends on industrial output vrery much. It is found out, that the more active the economic activity and production in the city, the worse is the ecological situation. According to World Health Organization the incidence of the population in advanced industrial areas is much higher, in comparison with the areas, where there is practically no industry [3].

Industrial sources of pollution generally consist of material and energy, which differently influence the environment. In detail, the structure of industrial pollution is presented in Fig. 3.

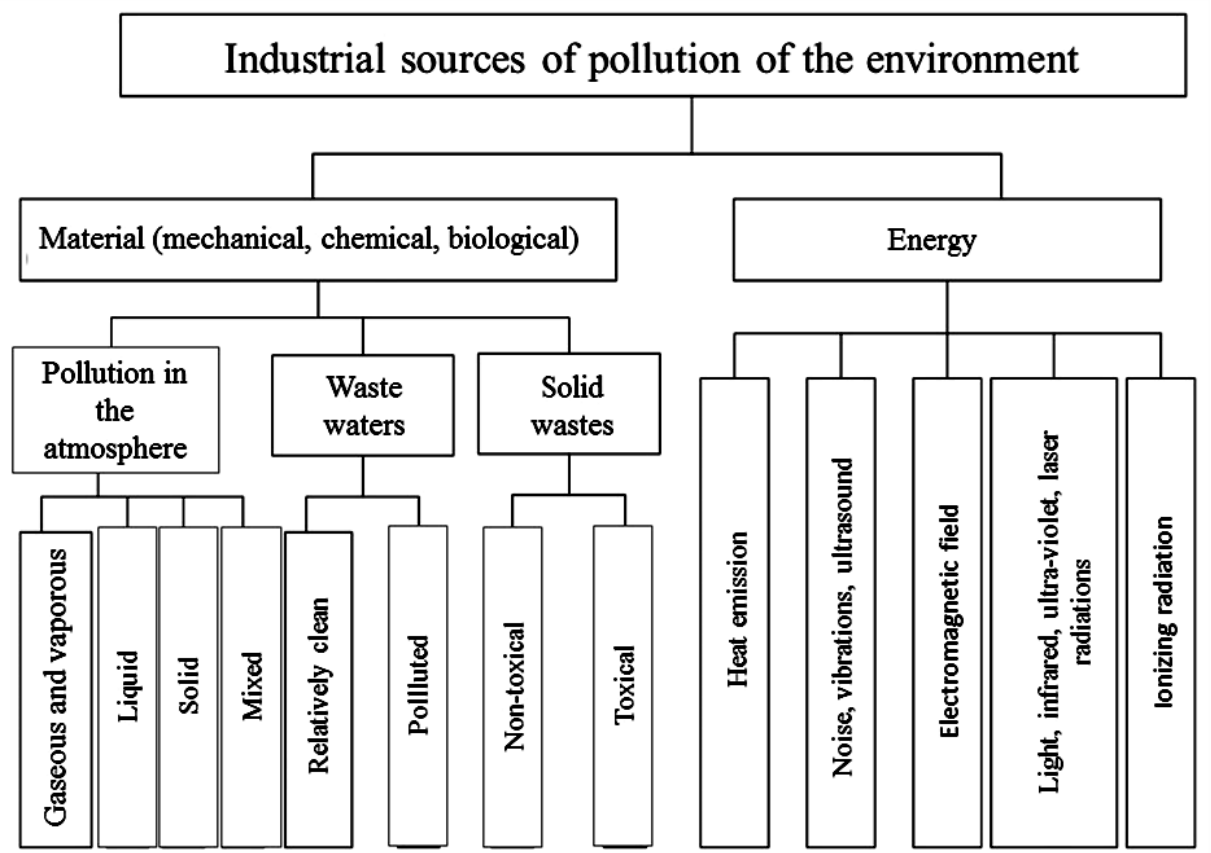

Fig. 3. Structure of industrial pollution. 
The pollutants, emitted by the industrial enterprises are various, according to their structure and harm level. The composition of substances depends on the outputs, quantity of sources as well as on the features of technological process of production.

The industrial enterprises, which throw significant harmful emissions include [4]:

- Heat supplying plants. Air pollution happens at the expense of such substances as nitrogen oxides, sulfur dioxide, sulphurous anhydride, dust, soot, ashes which contain salts of heavy metals.

- The enterprises of ferrous and nonferrous metallurgy pollute the environment sulphurous anhydride, oxides of nitrogen, hydrocarbon and mercury vapors.

- Machine-building production emits vapors of compounds of non-ferrous and heavy metals, including mercury vapors.

- Oil-processing industry emits carbon monoxide, hydrocarbon, hydrogen sulfide, sulphurous anhydride, ammonia etc.

- Enterprises of organic chemistry. Air pollution happens due to the large amount of organic substances to the difficult chemical composition, compounds of heavy metals and hydrochloric acid.

- The enterprises of inorganic chemistry emit free chlorine, hydrogen sulfide, oxides of sulfur and nitrogen and compound of phosphorus.

Besides air pollution, emissions of the enterprises influence other environments. The considerable danger is constituted by liquid industrial drains. One of the most widespread components of liquid waste are oil products, which can get into underground waters. As for catching of toxic and harmful impurity and also sewage treatment there are a lot unresolved tasks. The greatest number of water is used in chemical industry by production of chemical fibers and plastic $[5,6]$.

Sanitary classification of productions according to volume and degree of toxicity of the substances released with flue gases and ventilating air into the atmosphere, has defined the need of creation of protective zones between production and residential territories. Besides, the most rigid threshold limit the values of harmful substances in the atmosphere for most the enterprises are established now.

The absence or insufficient use of resource-saving and environmentally friendly technologies at the industrial enterprises leads to continuous accumulation of considerable volumes of production wastes, which considerably aggravate impact on the environment even at temporary warehousing in the territory of the enterprise.

In the cities, according to the state environmental monitoring, about 12-15 million tons of waste are formed in a year: $3.8 \ldots 5.1$ million tons of industrial wastes; $1.5 \ldots 3$ million tons of construction waste; 4.2 ..5.8 million tons of rainfall of treatment facilities of waterworks and stations of aeration; $0.1 \ldots 0.2$ million tons of medical waste; $0.15 \ldots 0.3$ tons of biological waste; 3...4.5 million tons of municipal solid waste (MSW).

The specifics of pollution of the city consist in the structure of production waste. The main part (90\%) forms waste of the industrial enterprises practically of all classes of danger. They are various on the chemical composition and contain more than 150 names of toxic connections. And the most dangerous that the share of the utilized components is rather high [7].

Along with others, waste of chemical, oil-processing industry and the biochemical productions dealing with highly toxic chemical elements and connections, bacteria and viruses are allocated. First of all, heavy metals belong to such chemical elements, because they are not subject to biochemical decomposition and easily get into a human body.

The analysis of technogenic pollution by industrial toxic waste in Russian cities according to total extreme concentration (TEC) proves that more than $25 \ldots .30 \%$ of territories are characterized high and maximum by levels of pollution and, therefore, the increased risk for health of citizens. Technogenic influence of the industrial enterprises influences the 
qualitative condition of water resources. As a result, criticality of the ecological condition of these cities is proved through formation of local crisis zones in the ecological-and-social aspect $[8,9]$

Some enterprises extended and could occupy considerable adjacent spaces, but others could not make it, because the housing estate very quickly has surrounded them. Now very few industrial enterprises which are in the city are effective and capable to further development. Due to the increase in prices for all the types of resources, including land and labour, the objects of the industry existing in the city have appeared in the adverse situation and forcedly reduce production. Fast aging of fixed assets is followed by production falling. This process is slowed in fuel industry, nonferrous metallurgy and oil chemistry thanks to the developed system of monitoring [10].

It has in turn put forward the task of environmental protection from harmful effects of the enterprises. The problem is being solved for a long time, in frequent cases since launch of this or that industrial facility. In some cases, it is explained by fast obsolescence of production technologies or mistakes during design, and in other cases toughening of the norms controlling extent of impact on the environment. Therefore, and the solution of these tasks in one cases is kept in the form of periodic work on maintenance and improvement of parameters of production, in other cases the modernization which is carried out time in several years will be required, and in the third cases it is possible to correct a situation only full-scale reconstruction.

Any industrial enterprise has close connection with the environment. It should be noted that the industry consumes a huge number of natural resources, however scales of this process in many respects are defined by low coefficient of the use of substance and energy. In particular, if the release of industrial output in Russia makes less than $25 \%$ of the level of 1990 , then the volume of the taken-away waters actually has remained at the previous level. Thus, the water-retaining capacity of production has sharply increased. The same situation has developed also with imported fuel resources. At reduction of total production consumption of fuel was reduced only by $18 \%$. A similar situation and with other resources that speaks about the increased resource intensity of industrial production in the cities of various countries of the world. The technological level of the considered production environment is higher, the problems of reconstruction which gain value town-planning and ecological are more difficult and more extensive [11, 12].

About 1000 medium-sized and large industrial enterprises of Moscow produce $8 \%$ of industrial output of Russia and $12 \%$ of consumer goods. About $60 \%$ of volume of profit of all enterprises and the organizations of Moscow is the share of the industrial sector, in which $20 \%$ of the working Muscovites is engaged.

So far, in the territory of Moscow there are more than 90 industrial and production zones including industrial, construction, municipal and warehouse, transport and other enterprises. At the same time their distribution extremely unevenly.

The main part of the city enterprises which did not undergone reconstruction for the last twenty years can be characterized by following factors: irrational placement of production capacities; imperfection of technological processes at the industrial enterprises; lack of effective clearing technologies; prevalence of low industrial and municipal building; excess by real zones of pollution of their own territory by $1.5 \ldots 2$ times; the master plans of the enterprises changed in development of production; the broken functional zoning, technological and transport communications; inefficient consumption of resources.

On fight against unfair owners of the industrial enterprises, not persons interested to spend additional resources for actions for reduction of negative impact on the environment, in the majority of the developed countries ecological audit is called. 
In the majority of the cities industrial facilities have appeared practically at once. Some cities were specially based for maintenance of large productions. But in the bulk, it is just a part of the city, which supports its economic, social, consumer and other spheres.

Today the industrial enterprises are the largest sources of replenishment of local budgets, the place of work of hundreds of thousands of people, the asset holder of engineering city facilities. Therefore, the matter of their future cannot be solved only from the point of view of preservation of an ecological situation. The thin mechanism allowing to define systemically opportunities, expediency, efficiency, a format of presence and work of this or that enterprise in the territory of the city is necessary. It is unconditional that to one of the first in this row is cost by matters of pollution of regional ecosystems.

Strategic objective of reconstruction of any industrial enterprise is the creation of the cumulative material and spatial conditions, ensuring ecological safety and overall performance as well as the stability of economic development. When planning reconstruction of large industrial facilities, it is necessary to start with the interests of people and long-term city programmes as the priority.

It is possible to apply the following formula, which allows to consider the optimum ratio of volumes of pollution and the territory under the enterprise in order to search of the objective decision:

$$
\mathrm{h}_{\mathrm{s}}=\frac{Z}{S}
$$

where $h_{s}$ - the specific admissible volume of pollution, accepted as constant value;

$\mathrm{Z}$ - total amount of pollution on the considered enterprise;

$\mathrm{S}$ - area of the territory of the considered enterprise.

Applying this formula for determination of admissible volumes of pollution or the area of various enterprises, we can divide the results three main groups, corresponding to the main options of reconstruction transformation of industrial zones. These options correspond to various schemes of development of the enterprises during the period of their functioning (fig. 4).

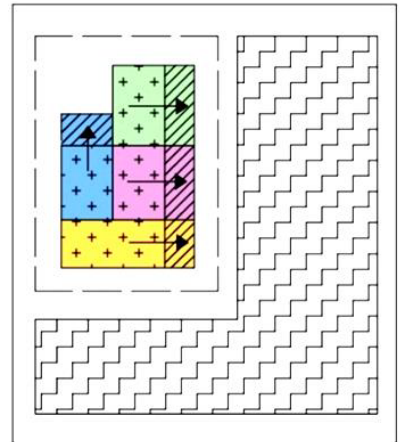

A

- Territory for further expansion
$+-\quad$ Initial size of the enterprise

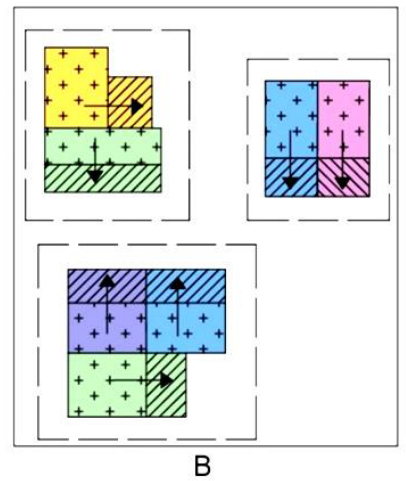

Q7 - Increase in dimensions in the framework of early reconstructions Maximum contamination limits

Fig. 4. Main schemes of development of the existing production facilities in the city.

In the sphere of industrial wastes there were some radical changes, determined by political, economic and social views. In the majority of the countries of Europe and North America waste management includes these obligatory stages:

- comprehensive programmes on decrease in volumes of formation of waste;

- widespread introduction of recycling of wastes, having consumer properties; 
- the use of possible waste as raw materials for other productions;

- extraction and use of energy potential of waste;

- decrease in consumption level external water and air in the technological line;

- introduction of modern scientific achievements in the system of cleaning;

- burial of the remains of waste on special technologies on ecologically neutral grounds.

Such approach to this problem is supported with acts, the corresponding organizational and financial mechanisms, in general, these steps are directed to creation of the conditions stimulating introduction of necessary methods of processing of industrial and consumption waste of resources.

Because of considerable rise in price of production, low level of modern technologies and deficiency of the corresponding equipment on processing, recycling some tens of types of waste of productions are subject. For this reason rates of their education and accumulation remain till present still rather high.

\section{Results}

1. The first option corresponds to the situation, when during functioning and development of the enterprise the production zones, adjoining the operating shops, but untied with them the general technology were formed. It has led to formation of compact placement of the enterprise with the combined or separate placement of auxiliary zones. In such cases zoning of the enterprises changed, however function charts of transport and utilities were not violated.

There are many examples, when the production centres were created as production associations, where the principle of cooperation with other enterprises for the increase in efficiency of the main production, subsidiary and auxiliary production, transport, energy service, engineering networks and constructions, etc. is used.

At the same time the intensive process of concentration as well as the growth of productions leads to the significant increase in the general energy, and, respectively, to the increase of negative impact on the city ecology.

This situation can be checked, applying the formula (1).

2. The second of the considered options corresponds to the situation, when there is the need of reconstruction of a rather enterprise. Such enterprises were designedaccording to ecological standards, close to modern, and in the conditions of good transport availability, and that explains the lack of the need for great warehouse spaces. Therefore, most such enterprises represent several groups of the shops, united by various stages of the technological line and evenly distributed across all the territory of the industrial platform. Reserves for development in the similar enterprises were put in intra shop space. Having sufficient engineering potential and on condition of periodic modernization of systems of cleaning, these industrial facilities are very seldom the sources of considerable ecological threats to the city space and practically all pollution remain within the territory of a facility.

Placement and development in the form of blocks of technological complexes gave the chance of through zoning at the growing enterprise and did not break the principle of zoning underlain in the original project. The lateral or rear faces can be a territorial reserve for the expansion of the enterprises of the second option. In certain cases perhaps slightly to increase the areas of the territory of the enterprises, having reduced territories of sanitary protection zones, but for this purpose it is required to create conditions for the reduction of volume and structure of production emissions.

Besides, territorial reserves can be created at the expense of on-site reserves (by elimination of small shops and the enterprises) and demolition of non-capital and invaluable houses, as well as elimination of the low-loaded railway tracks, merging of the small 
enterprises, cooperation of auxiliary farms, increase in number of storeys of production buildings of the existing enterprises.

During modernization of such enterprises the problem of complex use of raw materials, the fastest export of production wastes and by-products are essential for environment protection and for the increase in production efficiency.

Recently thousands of installations of gas purification and a pyleulavlivaniye are put into operation at the eco-friendly enterprises, more perfect technological processes allowing to reduce emissions of harmful substances and to reduce a resources consumption are introduced.

3. The third option corresponds to the special case of reconstruction, when the enterprises, which have undergone considerable changes of rather initial parameters are subject to transformation. It can be the carried-out early significant increase in energy, transition to release of other production, introduction essentially of other production technology, different from the design technology. Therefore, practically in all listed cases these transformations have led to increase in number of production shops within the industrial territory. At the same time each stage of development and reconstruction formed a new production zone, which has been technologically connected with the existing production. The general arrangement of the old or newly constructed corridors not always was evenly distributed. It has caused uneven distribution across the territory of warehouse buildings, treatment facilities, roads and engineering networks. Such development led to a chaotic arrangement of production and auxiliary zones on the master plan, to crossing of cargo and human streams, i.e. it broke integrity and clearness of the zoning put originally in the project.

In general, it explains the dispersed nature of pollution on the platform of an industrial facility and an exit out of its limits with the impact on nearby territories. Application of the formula (1) proves the expected result.

In case of difficult dismantling, the freed territory will be built up with new buildings and the social status of areas, which are considered as not prestigious and decayed for a long time will be raised.

Worldwide the considerable number of cases when the enterprises which are dangerous sources of pollution have been already removed for city boundaries is saved up.

Not only the enterprises having negative effect on ecology, but also the enterprises, noncore for the city, especially which are in a poor economic condition have to be subject to conversion, reforming and transfer and the enterprises, which are on the land plots, which is possible to be used more effectively both from economy, and according to requirements of city planning.

\section{Discussion}

Some criteria of decision making on transfer of the enterprise or production has to include the following aspects:

- considerable ecological harm, made by the enterprise to the environment, including already saved up damage;

- danger of a facility, meaning probability of emergence of emergency situations of technogenic character and their consequences;

- financial-and-economic position of the enterprise unsatisfactory for a long time;

- non-core nature of activity of the enterprise;

- insignificant volume of the sold products;

- causing damage to the city-planning image of the city;

- need for city-planning development of the territory, for example, according to Basic provisions;

- inefficiency of the use of the territory with its high potential value. 
From the point of view of financial expenses, this very expensive action, but actually it is the most effective [13].

It will be favorable to exempt the city from the industry for investors as well. In most cases the cost of repayment of the right of rent of the land plot occupied by the industrial enterprise decreases by the size of cost of transfer of the enterprises and the organizations, compensations of property rights of owners of buildings and other expenses.

At a partial conclusion of the enterprise it is necessary provide the following:

- possible reorientation of production structure;

- reduction of consumption of water, energy, raw material and material resources;

- rearmament of productions on essentially new ecologically "clean" technological basis.

Figure 5 presents one of the possible algorithms of making decision on the type of reconstruction of the industrial enterprise. It is obvious, that any options connected with preservation of an industrial facility in the city can be accepted only in case of positive the solution of an environmental issue. However, in case of the absence or in case of admissible negative impact on the environment from the plant or factory, the matter of a possibility of its safety in city space entirely lays down on definition of compliance to factors of placement of the enterprise in the city [14].

The offered algorithm is based on structuring various developed planning of the industrial enterprises in three most general options for which the situations with the ecological situation, corresponding to them in the occupied territory are defined.

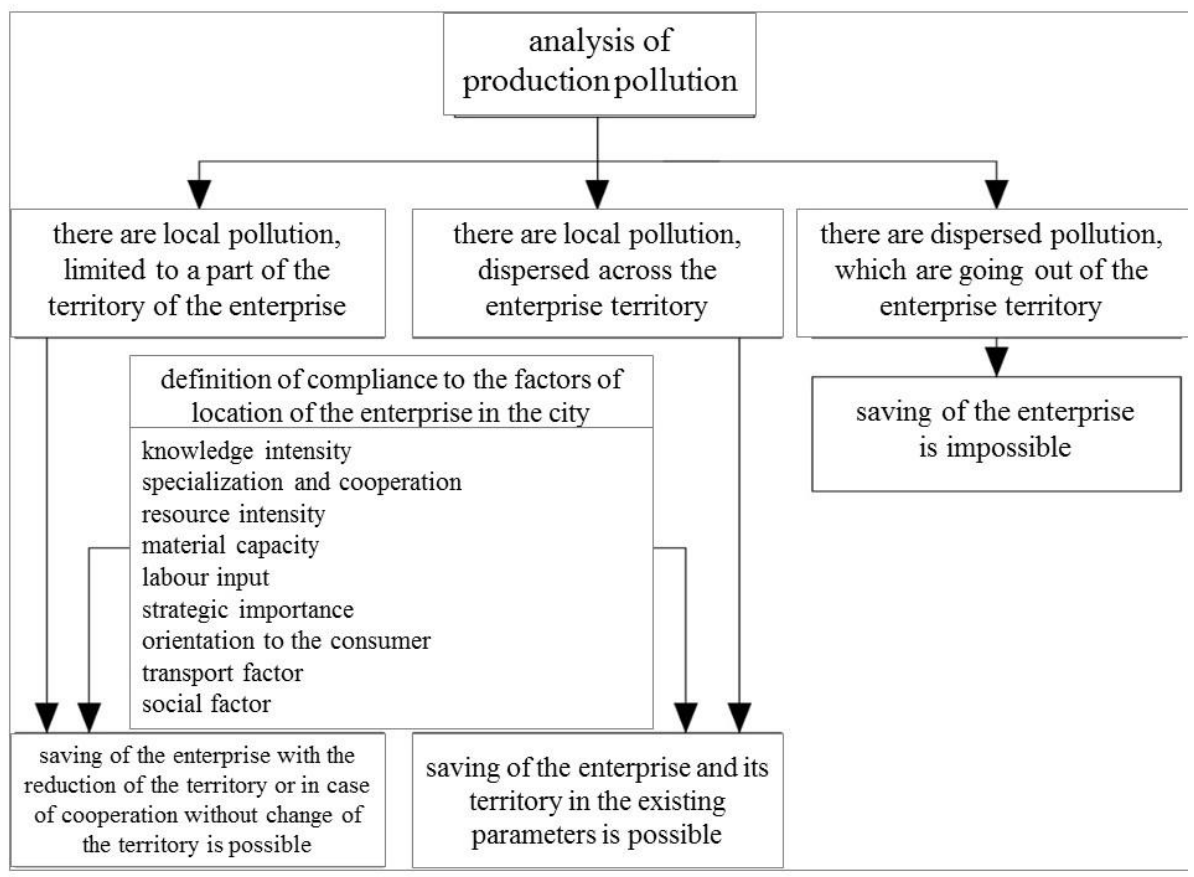

Fig. 5. Algorithm of making decision on the type industrial enterprise reconstruction.

\section{Conclusion}

Studying of experience of reconstruction of the enterprises as important facilities of the city structure proves the expediency of the following events: stage-by-stage conclusion of harmful productions; localization at the operating enterprises of production harm level; holding measures for the intensification of the use of the territories, occupied by the 
enterprises by the means of blocking of buildings; rational use of free spaces, the translation of warehouse and transport productions under the earth, increase in the number of storeys of production and administrative buildings and so forth.

In general, reconstruction of the industrial enterprises in the cities becomes the important factor, promoting the solution of such major city-planning problems as streamlining of placement of industrial regions in the system of the city and moving of the unprofitable and harmful enterprises in the sanitary relation out of its borders. It will allow to improve the ecological situation, to reduce the territories, used for the placement of productions, to improve the transport situation.

\section{References}

1. J. Shen, Y. Dennis Wei, Z. Yang, Journal of Cleaner Production 148, 785-794 (2017)

2. Sh. Jafarinejad, Petroleum Waste Treatment and Pollution Control, 19-83 (2017)

3. M.C. Kondo, Health \& Place 28, 31-37 (2014)

4. M.T. Lucas, Th.G. Noordewier, International Journal of Production Economics 175, 2434 (2016)

5. S. Pegov, Encyclopedia of Ecology, 204-210 (2008)

6. O.A. Rastyapina, N.V. Korosteleva, Procedia Engineering 150, 2042-2048 (2016)

7. D.T. Isitov, S.M. Muratbakiyeva, Young scientist 9-1, 35-39 (2016)

8. L.N. Blinov, Health as a basis of human potential: problems and ways of their decision, 2 (2013)

9. T. Verminskaya, V. Zinatullin, A. Kuhta, I. Rubtsov, E. Chibisova, Almanac of modern science and education 7, 37-39 (2008)

10. A. Mottaeva, Oil, gas and business 2, 6-8, (2011)

11. E. Chibisova, Journal of International Scientific Publications: Economy \& Business 5(2), $600(2015)$

12. E. Chibisova, Construction - formation of the environment of activity XI, 476-480 (2008)

13. T. Meshcheryakova, Energy saving 4, 36-41 (2015)

14. V.A. Novikov, A.V. Ivanov, Architectural and esthetic problems of reconstruction of the industrial enterprises (Stroyizdat, Moscow, 1986) 